\title{
Time and Organizational Improvisation
}

\author{
MARY CROSSAN \\ Richard Ivey School of Business \\ The University of Western Ontario \\ London, Ontario \\ Canada N6A $3 K 7$ \\ (519) 661-3217 \\ mcrossan@ivey.uwo.ca \\ JOÃO VIEIRA DA CUNHA \\ Massachusetts Institute of Technology \\ Sloan School of Management \\ Room E52-509 \\ 77 Massachusetts Avenue \\ 02139 Cambridge, MA \\ (617) 253-3857 \\ jve@mit.edu
MIGUEL PINA E CUNHA
Faculdade de Economia
Universidade Nova de Lisboa
1099-032 Lisboa - Portugal
351-21-382 2725
mpc@fe.unl.pt \\ Rua Marquês de Fronteira, 20 \\ DUSYA VERA \\ Richard Ivey School of Business \\ The University of Western Ontario \\ London, Ontario \\ Canada N6A 3K7 \\ (519) 661-3217 \\ dvera@ivey.uwo.ca
}




\title{
TIME AND ORGANIZATIONAL IMPROVISATION
}

\begin{abstract}
This paper argues that the apparent contradiction in current conceptualizations of time in organizations (e.g., Chronos vs. Kairos) is only apparent, and that a synthesis between these opposing poles is both possible and desirable. We propose improvisation (where time to plan converges with time to act) as a vehicle for articulating a dialectical view of time-based organizational phenomena, while focusing on the three major time-related problems organizations have to solve: scheduling, synchronization, and allocation. The paper discusses how improvisation helps to synthesize even time and event time in scheduling processes, internal pacing and external pacing in synchronization processes, and linear and cyclical time in allocation processes. Methodological and practical obstacles to synthesis are also discussed.
\end{abstract}

KEYWORDS: Improvisation, Planning, Time 


\section{TIME AND ORGANIZATIONAL IMPROVISATION}

Recently, an increasing number of scholars have examined assumptions about the phenomenon of time (e.g., Gherardi \& Strati, 1988; Jaques, 1982; AMR special issue 2001). As Goodman, Lawrence, Ancona and Tushman (2001) note: "Time as a subject of inquiry is pervasive and generalizable. It is a central issue in all disciplines of inquiry, from planetary physics to cell biology. Given the different manifestations of time in organizational life, there is surprisingly little research on time in this setting" (2001: 507). Indeed, Bluedorn and Denhardt (1988) assert that "time is as fundamental a topic as any that exists in human affairs" (1988: 316).

Despite the still emergent state of the research on time in organizations, managers' vocabulary is full of references to time. When describing strategy, concepts such as just-in-time, time-to-market, time pacing, reaction time, and timing are frequently mentioned. Particularly in the context of highly dynamic and unpredictable environments, time is a resource that needs to be actively managed in order for firms to remain competitive. Consequently, decisions about pace, transitions, rhythms, and cycles, among other time-related choices, have achieved increasing strategic relevance (e.g., Ancona \& Chong, 1996; Brown \& Eisenhardt, 1997, 1998). The management of time is, however, complicated by the multiple conceptualizations and assumptions of time that currently exist.

One prevalent time dichotomy is that of Chronos and Kairos, in which Chronos (the greek god of "objective" time) presents time as an objective, homogeneous phenomenon unfolding along an infinite continuum, and Kairos (Zeus' son, god of “appropriate" time) sees time as a subjective heterogeneous phenomenon enacted by social actors. In addition, in their 
review of the literature Ancona, Okhuysen, and Perlow (2001) list several types of time that provide answers to the question "What is time?":

... in contrast to the linearity that clock time suggests, there is cyclical time, in which events repeat over and over... in contrast to being infinitely divisible, time may be continuous and indefinite. Other distinctions include contrasting objective time with subjective time, homogeneous with heterogeneous, regular with irregular, precise with imprecise, reversible with irreversible, objective with experiential, closed with open, and clock time with event time. (2001: 515)

Some scholars argue for the need to consider these alternative views of time in organizations (e.g., Burrell, 1992; Clark, 1990; McGrath \& O'Connor, 1996), while others call for the implementation of new conceptions superior to existing ones (e.g., Ciborra, 1999; Eisenhardt \& Brown, 1998). In spite of these different approaches, authors seem to agree that assumptions about organizational time-based phenomena can be placed in a set of continua bordered by pairs of contradictory concepts. The presence of these tensions appears to indicate that someone seeking to understand organizational phenomena from a time-based perspective is deemed to chose from either one set of assumptions or its antithesis, limiting the scope of one's findings ex ante.

In contrast to this perspective, we propose that a synthesis of the apparently contradictory views of time is in practice not only possible, but exactly what managers need to pursue in order for firms to remain competitive in today's environment. Previous research has suggested the possibility of this synthesis. In fact, Burrell (1992) argues that time need not be perceived either linearly or cyclically, but that it can be thought of as a spiral--a synthesis between both. Burrell only hints at what this concept would mean, nonetheless, he points out that such a synthesis is indeed possible and that it has more descriptive power than either one of its poles. More 
concrete is the work of Orlikowski and Yates (1998), who successfully point out that the dichotomies of Chronos/Kairos are false and that they are different sides of the same coin.

In this paper we build on previous efforts towards synthesis and propose improvisation as the organizational process that allows for the integration of the apparent opposite views of time. Improvisation is closely associated with time, as can be noted in definitions that describe it as action that occurs extemporaneously, in the nick of time, and in real-time. We argue that improvisation is an ideal basis for understanding time-based organizational phenomena dialectically because improvisation itself is a process closely linked to time and has an intrinsic dialectical nature, blending conflicting concepts such as planning and acting, discipline and freedom, control and spontaneity. Weick (1998b) argues that although organizational analysts are often tempted to choose between conceptual dichotomies, "the issue in most organizations is one of proportion and simultaneity rather than choice" (1998: 551). He adds that improvisation helps to reconcile organizational tensions, because "it is a mixture of the pre-composed and the spontaneous, just as organizational action mixes together some proportion of control with innovation, exploitation with exploration, routine with non-routine, automatic with controlled" (Weick, 1998b: 551).

The objectives of this paper are to use improvisation as a vehicle for articulating a dialectical view of time-based organizational phenomena and to propose improvisation as a critical skill for effectively managing time in organizations. However, this is not about the tactical considerations of time management. Rather it is about how time is viewed and managed in a more strategic sense. With this purpose, we focus our analysis on the three major timerelated problems organizations need to solve and their associated dichotomies scheduling (even/event time), synchronization (internal/external pacing), and allocation (linear/cyclical 
time) (Gherardi \& Strati 1988, Hassard, 1996). Through scheduling, synchronization, and allocation, organizations achieve temporal coordination. Temporal coordination formalizes and standardizes organizational time and space, giving form to a homogenized system of activities, roles, and expectations (Holmer-Nadesan, 1997). We discuss the opposite views of time involved in scheduling, synchronization, and allocation, and describe how improvisation helps firms to synthesize even time and event time in scheduling processes, internal pacing and external pacing in synchronization processes and, finally, linear time and cyclical time in allocation processes. Furthermore, we suggest that this synthesis, achieved through improvisation, is linked to positive firm performance and has important implications for management practice.

First, we define improvisation and describe its incidence in firms. Then, we examine the processes of scheduling, synchronization, and allocation, and discuss the role of improvisation as a means towards temporal syntheses. Finally, we acknowledge the challenges of synthesis and present conclusions, implications, and directions for future research.

\section{ORGANIZATIONAL IMPROVISATION}

Most definitions of improvisation include a reference to time: "intuition guiding action in a spontaneous way" (Crossan \& Sorrenti, 1997: 156); "the degree to which composition and execution converge in time" (Moorman and Miner, 1998a: 702); "bringing to the surface, testing, and restructuring one's intuitive understanding of phenomena on the spot, at a time when action can still make a difference" (Weick, 1996: 147); "the conception of action as it unfolds, by an organization and/or its members, drawing on available cognitive, material, affective and social resources" (Cunha, Cunha \& Kamoche, 1999: 302). All of these definitions, in a more implicit 
or explicit fashion, show that improvisation is, in essence, a time-based phenomenon because of its focus on the timing of conception of an action and its execution.

As Crossan, Lane, White and Klus (1996) suggest, improvisation is an activity where planning meets opportunity, blending in this way strategy formulation and implementation. Weick (2001) also calls improvisation "just-in-time strategy" and explains that, "Just-in-time strategies are distinguished by less investment in front-end loading (try to anticipate everything that will happen or that you will need) and more investment in general knowledge, a large skill repertoire, the ability to do a quick study, trust in intuitions, and sophistication in cutting losses" (2001: 352). These descriptions of improvisation in the context of business are consistent with the experience of improvisational jazz. Jazz improvisation has been used to illustrate how basic musical themes are reworked in a spontaneous fashion to build novel outcomes. Berliner's definition of jazz improvisation reinforces the notion of improvisation operating at the juncture of planning and opportunity: "Improvisation involves reworking pre-composed material and designs in relation to unanticipated ideas conceived, shaped, and transformed under the special conditions of performance, thereby adding unique features to every creation" (1994: 241).

Given the focus of multiple definitions of improvisation on adaptability and innovation, there has been a tendency for researchers to assume that improvisation may be a superior form for organizational action. In addition, there has been a focus on "effective" improvisation, where improvisational expertise is clearly present. However, as Vera and Crossan (2001) point out, improvisation is not inherently a good thing. There are conditions under which improvisation is likely to occur, and conditions under which it is likely to be effective (e.g., Crossan \& Sorrenti, 1997; Moorman \& Miner, 1998a). 
Although elaborating on many of these conditions is beyond the scope of this paper, we focus in this section on describing the incidence of improvisation in organizations, and in particular on pointing out the different conditions supporting planning and improvisation in firms. Understanding the occurrence of improvisation and its interaction with planning is important in order to understand the role improvisation plays in processes such as scheduling, synchronization, and allocation. Although there is a strong planning paradigm in strategy research and practice, and a strong managerial preference towards routinization and control, there is evidence in the literature that improvisation is more common in organizations than managers may think (e.g., Mintzberg \& McHugh, 1985; Pascale, 1984; Peters \& Waterman, 1982; Rerup, 2001). Barrett (1998) explains,

Managers often attempt to create the impression that improvisation does not happen in organizations, that tightly designed control systems minimize unnecessary idiosyncratic actions and deviations from formal plans. People in organizations are often jumping into action without clear plans, making up reasons as they proceed, discovering new routes once action is initiated, proposing multiple interpretations, navigating through discrepancies, combining disparate and incomplete materials and then discovering what their original purpose was. To pretend that improvisation is not happening in organizations is to not understand the nature of improvisation. (1998: 617)

We relate planning and improvisation on the basis of two dimensions, time pressure and uncertainty, which have been frequently suggested as stimuli of improvisational processes (Moorman \& Miner, 1995; Vera \& Crossan, 2001). Under abundant time and low uncertainty, managers can control their environment through detailed analysis, with a "planning" orientation (Crossan et al., 1996) and may see no need for exemplary performances against the script. However, under conditions of time pressure and/or uncertainty, a planning orientation is insufficient and improvisation is proposed as an alternative or complementary orientation. It is not only likely to occur in these circumstances, but also likely to lead to better firm performance. 
In the following paragraphs we provide several examples of organizational improvisation that vary depending on the level of time pressure and uncertainty.

A first scenario of organizational improvisation is one in which there is time pressure and urgency to respond to an unexpected opportunity or problem, but a low level of uncertainty. Planning is not possible, because there is no time to plan. Failing to respond in the moment may result in a lost opportunity or in the intensification of the problem. However, environmental cues are clear and what firms need to do is to structure their response quickly. In this scenario, improvisation is characterized by a high level of spontaneity, a low level of creativity, a strong influence of prior plans and routines, and straightforward combinations of knowledge and experience. These improvisations do not represent original creations, but instead extemporaneous deviations from present models. They merge planning and executing, by allowing individuals to use their intuition, to act, and to incrementally adjust to changes in the environment. Moorman and Miner (1995) provide examples of this scenario in the context of new product development when the teams they studied had to improvise new marketing campaigns in response to clients' or competitors' feedback on previous product positioning efforts.

Another common improvisational scenario is one in which time is not the problem: uncertainty is. Even if there is time to plan, planning is unlikely, since individuals are frustrated by either too few or too many possible interpretations of unexpected events. Improvisation is helpful under these circumstances because it makes retrospective sensemaking possible. By improvising, instead of planning and then acting, people act and then make retrospective sense of their experience, so that they can act again. Examples of this scenario are abundant in the context of experimentation in new product development, including pharmaceutical drug 
development, or software development. While the execution of an experiment usually involves an iterative cycle (Thomke, 1998) of design, build, run, and analyze steps, as environmental turbulence increases these four phases start to overlap and to be executed simultaneously (e.g., Brown \& Eisenhardt, 1997; Eisenhardt \& Tabrizi, 1995; Iansiti, 1995; Leonard, 1995). Under these circumstances, experiments are no longer planned and controlled, but become improvisational. Improvisation enables individuals and firms to take action without knowing how it will unfold, and to find structure through that learning process. This improvisation is characterized by a low level of spontaneity, a high level of creativity, and a rich combination of past knowledge and expertise. The example of the development of the "Post-it-note" (Frost, 1995; Peters \& Waterman, 1982) is an example of this scenario. The application of a "failed" glue to the problem of securing temporary placeholders on sheets of music, demonstrates rich combination with a high level of creativity. There was a low level of spontaneity given low time pressure, but a high degree of uncertainty regarding the application and commercialization of the product, which required individuals to take actions and learn from the outcomes.

Finally, the most challenging improvisational scenario is one in which planning is impossible, because time is scarce, and the environment is undecipherable. Crisis situations and rapidly changing and unpredictable environments are characterized by these conditions of urgency and uncertainty. Firms that still try to plan under these conditions find themselves frustrated by the simultaneous pressure to act and the inability to understand what is going on around them (e.g., Roux-Dufort \& Vidaillet, 2001). On the contrary, having decided to improvise, individuals "wade into situations with fallible knowledge, secure in the belief that they can recombine that knowledge by shifting their fallibilities around. Faith in their ability to 'make do' infuses confidence into their balance of knowledge and doubt" (Weick, 1998a: 59). 
Improvisation in this scenario is characterized by high levels of spontaneity and creativity. The Mann Gulch disaster (Weick, 1993) is a well-known example in which a firefighter, under severe time pressure, departed from prior routines (e.g. dropping his tools, and creating a fire in front of him) to escape death. Tragically, the other firefighters, who clung to previous routines, perished.

In summary, we define organizational improvisation as a process that is simultaneously extemporaneous and creative, and describe it as a common response when individuals and groups find themselves in situations in which they need to act, but lack the time to plan and understanding of the environment. While we acknowledge, with the mainstream of contingency theory, that a pure planning mode may be the appropriate response in situations where there is neither time pressure nor uncertainty, we suggest that managers need to assess when it is time to plan and when it is time to improvise.

In the remainder of the paper, we address the relationship between time and improvisation in situations of time pressure and uncertainty. To delve more deeply into the improvisation-time link, the next sections examine the role improvisation plays in three dialectical aspects of time: event time vs. even time (scheduling); internal pacing vs. external pacing (synchronization); and linear time vs. cyclical time (allocation).

\section{SCHEDULING: EVENT TIME VS. EVEN TIME}

A first synthesis allowed by an improvisational perspective on time-based organizational phenomena is related to the problem of scheduling, meaning the establishment of deadlines and the positioning of activities on the continuum of time (Ancona et al., 2001). The problem of scheduling embodies two different approaches to time--event time and even time. Event time is a time whose passage is perceived through the occurrence of "meaningful events, including those 
that are related to seasonal variations" (Bluedorn \& Dernhardt, 1988: 304). Even time, or clock time, is a time whose passage is perceived through the flow of "equalized, cumulating units, [with] non-valuative acceptance by large geographically dispersed populations, open[ed] to unlimited extension and with no particular concern for the past, present, and future" (Bluedorn \& Dernhardt, 1988: 305).

Managing on event time means managing with a focus on flexibility, the goal being to respond to internal and/or external changes or events (e.g., a natural disaster, the entry of a new competitor, CEO resignation) in order to maintain or sustain the organization's competitive position. This type of management may be either reactive or proactive, if one understands proactivity as a reaction to a socially constructed vision of future changes (Smircich \& Stubbart, 1985). Planning does not seem to be highly popular amongst those espousing event-time management because of the intrinsic unpredictability of those events that are used to determine the march of time (Eisenhardt \& Brown, 1998, Mintzberg, 1994; Peters, 1992).

Event-time management has been in the foreground of practitioners' and researchers' concerns because of the expanding perception of hyper-competitive environments (D'Aveni, 1995) leading to new competitive landscapes (Bettis \& Hitt, 1995) that force organizations to constantly change and adapt. Indeed, whole areas of management research owe their emergence as legitimate and popular topics to this perception and, ultimately, to this approach to time and organization. The recent application of complexity science to organization studies (Stacey, 1991, 1996) is but one of many possible examples. Moreover, it is not an overstatement to attribute much of recent management concern to the perception that "change is the only constant" and that organizations must strive for ever-flexible adaptation--a reformulation of what 
event-time management is all about (Crainer, 1997; Micklethwait \& Woolridge, 1996; Shapiro, 1995).

In contrast, managing on even time is managing with a focus on manipulation. Because industries are defined by value propositions that are socially constructed and which tend to crystallize into autopoietical or similar perceptions of the market (Maturana \& Varela, 1980), the ability to think outside the dominant industry paradigm enables an organization to manipulate the market by reshaping it through the fundamental restatement of its value proposition (Hamel \& Prahalad, 1994). Canon's redefinition of the copier industry through the personal copier is an example of such a change.

Even-time based management also builds on research that shows that change is most often triggered by temporal shifts and not by actual "problems" (Tyre, Perlow, Staudenmayer \& Wasson, 1996). These temporal shifts can be either purposefully intended, such as a mandatory break during a project in order for people to reflect, or accidental, such as a breakdown in an assembly line, which gives crew members an "empty" time (Tyre et al., 1996). Additionally, Gersick's study on group behavior and deadlines shows that the passage of clock time is responsible for a punctuated change in behavior, from mostly reflective to mostly active (Gersick, 1991, Gersick \& Hackman, 1990). Integrating these research efforts, even time seems to play at least three different roles in enhancing flexibility and change. Firstly, it is a trigger for change. As Gersick's (1991) work shows, groups with very different characteristics change their behavior when approaching the middle of the span of time they have to perform a given task. Secondly, even time acts as a coordination mechanism for change, by creating a shared calendar for change and thus serving as a control mechanism that schedules activities in order to maximize their synchronization (Hedberg, Nystrom \& Starbuck, 1976; Zerubavel, 1987). 
Finally, even time is a resource for change, providing organizational members with the temporal space they need to reflect and conceive that change (Tyre et al., 1996). In this light, planning assumes a very different role to the one it plays in event-time management. Planning aims to enable coordination, but it does so, not by establishing deadlines on a case-by-case basis but, instead, by dictating the rhythm/pace of the organization through the explication of its major change cycles (Eisenhardt \& Brown, 1998).

We synthesize even and event time by defining even-event time management as one focused on manipulative flexibility, which we conceive as responding to changes in the environment--being flexible--in order to shape that same environment. This argument is based on descriptions of industry revolutions that reveal them to be less often the result of acts of creative genius than of a mixture of serendipity, good fortune, and hard work (e.g. Pascale's (1995) description of the entry of Honda into the U.S. motorcycle industry). This amounts to a view of change and adaptation as an incrementally-punctuated phenomena, where local adaptations often result in long-term discontinuities, a mode of change characteristic of organizational improvisation. In fact, Brown and Eisenhardt's (1997) research on fast-paced industries shows that many changes in its members' strategy and organization occurred in a process akin to the gradual heating of water (incremental change) that eventually evaporates (punctuated change). Additionally, Johnson and Rice's (1984) and Orlikowski’s (1996) research into computer-mediated work and its implementation, shows that discontinuous changes in organizational processes and practices often arise because of a stream of improvisations in the technology's implementation process.

We argue that both even time and event time are required to manage firms in turbulent environments, in which the high rate of change frequently creates conditions of urgency and 
uncertainty. Clark's (1985) research on a marketing group within a large hosiery firm suggests that an event time orientation may be more suited to organizations in turbulent environments. He found that group members possessing a heterogeneous time reckoning clearly outperformed the others, who possessed a homogeneous one, because of their ability to adequately respond to unexpected events. However, even in environments with high time pressure and uncertainty, even-time management plays a critical role. Brown and Eisenhardt (1997) discovered in a largescale research project on the computer industry that regular transitions and calendar-based deadlines (e.g., launch a new product every two years) allowed for more successful and timely innovations than through purely event-based ones (e.g., launch a new product in response to a competitor's move or to a new upstream technology). They concluded that a combined approach was effective, and suggested improvisation as being critical. They argued that the "real-time" feature of improvisation in organizational settings allowed enough room for interim calendarbased deadlines (even time) to be put in place in order to enact the necessary flexibility for a speedy and timely reaction (event time).

The practice of organizational improvisation provides a synthesis between even and event time-based management, enabling organizations to attain the highest level of resilience from a temporal standpoint. Research on new product development has shown that execution rarely follows the path traced by planning, and as a result, deadlines are seldom met. When deadlines are met, there is often some sacrifice as far as product quality is concerned (Cooper, 1979). Nonetheless, meeting a deadline may be one of the most important features of a new product launch, especially as far as profitability goes (Craig \& Hart, 1992; Deschamps \& Nayak, 1995). Recent studies on this process espousing an improvisational view (Miner, Bassoff \& Moorman, 2001; Moorman \& Miner, 1998a, 1998b) have shown that improvisation can be used 
effectively to ensure that unforeseen events are handled (event-time management) in order for deadlines to be met (even-time management), and profitability assured.

Organizations comprise multiple time-worlds, each part of the ensemble working to local and distinct rhythms. Different perceptions of time in an organization, or between organizations, need to be reconciled to enable coordination (Zerubavel, 1982; Waller, Gibson \& Carpenter, 1999). As in improvisation, organizations strive to achieve integration and temporal symmetry through plans intended to create the minimal commonality necessary for engendering action without prescribing it (Hedberg et al., 1976; Kamoche \& Cunha, 2001). What such plans aim for is generating a compatible temporal perception, rather than a shared one. The elements contained in this type of plan are mostly circumscribed by calendar-based deadlines, the strategic intent (as opposed to the means to get there), and overarching action principles, allowing for both "even-time" proaction and "event-time" reaction (Crossan et al., 1996; Crossan \& Sorrenti, 1997; Perry, 1991). In summary, the ability to improvise enables firms to remain competitive by respecting calendar deadlines while dealing with internal and external events.

The foregoing discussion leads to the following proposition:

P1: Under conditions of high time pressure and/or uncertainty, a synthesis of event-time and even-time management through improvisation is associated with positive firm performance.

\section{SYNCHRONIZATION: INTERNAL PACING VS. EXTERNAL PACING}

Synchronization is about establishing temporal relationships between activities (Ancona et al., 2001) and aligning the pace of effort among organizational members and with the environment. We differentiate in this discussion between internal and external pacing depending if these rhythms exist inside or outside the boundaries of the firm. External pacing differs from 
event time in that some events are internal, occurring within the organization (e.g. products are finished, results come out of R\&D).

The issue of whether the organization should set its pace by internal/rational choice or external considerations is an issue of synchronization: which are the rhythms that it should pay most attention to, its own, or those of the environment? Internal pacing contends that the speed or pace of action that an organization assumes should be decided in a contingent way, taking the environment and relevant stakeholders into consideration but keeping the final decision to itself (Lawrence \& Lorsch, 1967). This is the dominant theoretical position, recently translated by both academicians (e.g. Eisenhardt \& Tabrizi, 1995; Ellis, 1982) and gurus (e.g. Stalk \& Hout, 1990; Kao, 1997) into efforts to speed up organizations. Each part of the organization has its own rhythms, which are socially constructed cultural artifacts (Berger \& Luckmann, 1967; Clark, 1990) that, to be synchronized, require planning and explicit organizational coordination mechanisms. Thus, this approach to time in organizations elevates fast organizations to the role of models upon which others have to benchmark and set their standards (Eisenhardt \& Tabrizi, 1995; Eisenhardt, 1997). Speed is the ultimate organizational competence in the path for "the necessary disorganization for the nanosecond nineties" (Peters, 1992, emphasis added). In this view, speed is not only the yardstick of success at the organizational level but also at the individual level. In fact, the degree of success of one's career is often defined (although more implicitly than explicitly) by "the rate or sequence by which he or she passes [...] through stages which relate the various positions and identities available in the society" (Hassard, 1996: 591). This means that the success of an individual is directly proportional to the pace at which she/he is promoted either in an organization or at the broader social level (Hughes, 1971). Summing up, 
individual and organizational speed of action, reaction, and progression can be manipulated, and the more they are, the more successful that individual or organization will be perceived to be.

Recent research on organizational phenomena from a time-based perspective has challenged this assertion and its underlying assumptions. The importation of the "entrainment" concept from the biological sciences to the social sciences in general, and to organization science in particular, allowed organizational scholars to uncover chronological interdependencies between different parts of the organization, and between the latter and its environment (e.g. Ancona \& Chong, 1996). "When" was added to the "what", "how", "who", and "why" of change. Time emerged as an important element in organizational change, serving as a trigger, resource, and coordination mechanism (Tyre et al., 1996). Research by Ancona and Chong (1996) and by Eisenhardt and Brown (1998) shows that more important than striving to act, react, and progress faster and faster, is attuning action, reaction, and progress to relevant rhythms--be they internal (in the organization) or external (in the environment). Drawing on research on implementation and rollout of administrative and product innovations, these scholars found that those that were introduced respecting organizational and relevant stakeholders' rhythms, were more successful than those that did not, thus shedding a new light upon the issue of synchronization. In this view, model organizations are those that are able to synchronize with the pace of those phenomena underlying their activity and not to do so with an arbitrary vision of what adequate speed should be. Managers, thus, play a very different role under this understanding of time. Their role is to foster the consideration of relevant rhythms (Clark, 1990) so that these can be incorporated as members enact their temporal structures when acting, reacting, and progressing (Orlikowski \& Yates, 1998). 
A synthesis between these two apparently contradicting perspectives is, again, not easy to find. However, this is only so if we perceive the internal and external rhythms, and the need for higher speed of action as objective realities. If we see reality and time as socially constructed (Berger \& Luckmann, 1967) and these rhythms as enacted phenomena (Weick, 1979, Smircich \& Stubbart, 1985) then an integration of the "faster is better" and the "entrainment" approaches seems feasible. In fact, one could argue that time depends on the interpretative ability of the connecting consciousness. Thus if one fails to sensemake (Weick, 1995) patterns out of the changes occurring in the relevant environment, the latter will appear chaotic and uncertain, and entrainment will be close to impossible (Bluedorn \& Denhardt, 1988), as the aforementioned research performed by Clark in the hosiery firm clearly exemplifies (Clark, 1985). In this light, the integration between the two conceptions of synchronization appears not only possible, but also possibly desirable. We propose that organizational improvisation contributes towards this end.

Organizational improvisation allows firms to respect the pace of relevant stakeholders and environmental rhythms, without disrupting the internal pace of the organization. The underlying process that makes this feasible is conceiving a response in real time--improvising-whenever a difference in pace, cycle, and/or rhythm between the organization and its environment would call for a resetting of the former's enacted time structure (Orlikowski \& Yates, 1998). This improvisational ability is particularly relevant in contexts characterized by time pressure and/or uncertainty. In fact, Brown and Eisenhardt's research shows how companies in the fast-changing computer industry are able to maintain their internal rhythms of product development in a very turbulent market through "multiple product innovation [which] involves improvisation of current projects through limited structures and a real-time 
communication $[\ldots]$ form[ing] a core capability for creating frequent, relentless and endemic change that is associated with the success of firms in high-velocity, competitive settings" (Brown \& Eisenhardt, 1997: 32, emphasis added). In addition, through improvisation, organizations can, purposefully or not, shape the rhythms of their environment, since the speed gained through improvisation may allow the firm to set the standard pace for the industry.

In summary, improvisation synthesizes internal and external pacing by allowing organizations to achieve high levels of speed either by taking advantage of external rhythms, or by shaping these rhythms themselves. In this setting, the role of the manager shifts from speeding up the organization or entraining it to its environment, to fostering a selective social construction of the relationship between the signifiers of time and its passage (McGrath \& Rochfort, 1983).

The previous discussion leads to the following proposition:

P2: Under conditions of high time pressure and/or uncertainty, a synthesis of internal pacing and external pacing through improvisation is associated with positive firm performance.

\section{ALLOCATION: LINEAR TIME VS. CYCLICAL TIME}

The debate between those advocating that time is a linear phenomenon and those advocating that time is cyclical, is perhaps one of the most discussed topics of time-based organizational phenomena research (Das, 1993). The focal point of this debate has been the demonstration that the linear perception of time is dominant in the so-called "western" countries and that that this pervasiveness is responsible for fundamental assumptions about work and life (Katz, 1980). We chose to position our discussion of these two categories of time at a lower level of abstraction, relating it not to social paradigms but to organizational practice. At this 
level, the debate mostly concerns the issue of allocation, which involves specifying the time and resources to be spent on specific tasks and activities. The discussion about linear and cyclical time is part of the allocation process, because each of these competing views of time has important effects for the corporate planning process, which essentially maps out the allocation choices to be made by the organization regarding time, money, and people (Mintzberg, 1994).

Starting with the perception that time is a linear phenomenon, where the past is never repeated and always different from the future (Hassard, 1996), one can rightfully expect planning to be concerned with one of two tasks. First, if the organization at large believes the future to have a continuous relationship with the past, then planners will occupy their time with finding the more adequate methods to extrapolate the former from the latter. Second, if the organization believes that the relationship between the future and the past is a discontinuous one, then planners will be more concerned with preparing the organization for future contingencies (scenario planning is often misunderstood as being the privileged technique to tackle this challenge; Pascale, 1999; DeGeus, 1997).

As mentioned previously, independent of the assumed relationship between past and future, planning under a linear view of time has a limited use for the past, since the past will never be repeated. The role of the past is often limited to either serving as a quantitative input for time-series analysis (continuity between past and future) or as a qualitative input for visionary strategy making (discontinuity between past and future). Learning is thus limited to making the past as explicit as possible in order to integrate it in strategy formulation, and to forget it when it comes to implementation. Consequently, managers are called to "fold the future into the present" (Kavanagh \& Araujo, 1995), i.e. to anticipate future contingencies and decide, in the present, how to allocate current resources so that when those contingencies appear, the 
organization is able to respond. An important point to make in this discussion is that this is not necessarily a reactive stance. The "revolution" of industries advocated by Hamel and Prahalad (1994) also espouses a linear view of time in the sense that it uses the past to design the future by attempting to "outsmart" that past (which is encapsulated in the socially-constructed view of the industry) by creating a new value proposition and qualitatively shifting the industry's competitive basis.

In contrast, under a cyclical view of time, the past is seen as occurring again and again. In this conceptualization, planners invest time detecting which past routines and action schemes are necessary to handle present circumstances. The environment is perceived to revolve around a socially-constructed set of stages (e.g., the seasons of the year, political election cycles, or business cycles), and at each of these stages the organization has to perform an identical action routine, cycle after cycle (e.g., bring in the harvest, make political donations, lay off staff). Clark's (1978) research into sugar beet production is an example of how organizations adopt different sets of behaviors under different environmental conditions that repeat cyclically, year after year.

In this type of setting, learning is again concerned with explication of the past. However, under a cyclical view of time the past is not used as an input for deciding on new routines and behaviors, but instead "old" routines and behaviors are enacted again and again as the perception of the repetition of environmental cues is socially constructed. In this sense, organizational competence is defined as the ability to recognize the past in the present and, thus, when planning, the "then" is folded into the "now". Consequently, the allocation of current resources is closely linked to past allocation decisions. The future is seldom a concern until it becomes 
present, because one can adequately expect that it will be little more than the past emerging again and again--be that future the next year or the next week (Ditton, 1979; Cavendish, 1982).

Time in turbulent environments can hardly been described as only linear or cyclical, but more precisely as a combination of both. As stated in the introduction, a few authors have already sketched a synthesis between these two perceptions of time (e.g., Burrell, 1992; Filipcove \& Filipovec, 1986). Filipcove and Filipovec (1986) represented "spiral time" as a snake biting its tail and a body in fetal position. However, Burrell (1992) contends that "how one would illuminate a course on the management of change using solely a picture of the body in fetal position or the coiled serpent is not immediately apparent" (1992: 169). Burrell's (1992) own discussion provides few management implications because his discussion treats either very macro phenomena (post-modernism and anarchy) or very micro ones (absenteeism and sabotage), making the task of understanding the enactment of these phenomena at the organizational level a difficult one to tackle.

A starting point towards a synthesis would be to juxtapose the prior conceptualizations of linear and cyclical time. This would result in the following statement: linear-cyclical time management consists in folding the past and the future into the present. Based on this statement, a synthesis between cyclical and linear time would have the present as its main stage, such as is the case in organizational improvisation (Ciborra, 1999). In fact, the major underlying elements of improvisation (inside and outside organizational settings) are the existence of a few rules and a basic plan of action--which folds the future into the present--and creativity, expertise, and bricolage (the reworking of pre-composed routines and resources to handle present challenges)-which folds the past into the present (Crossan, 1998; Hatch, 1997; Weick, 1999). Organizational 
improvisation is thus proposed as a meeting place between cyclical and linear perspectives of time.

Particularly in contexts of time pressure and/or uncertainty, planning under a "spiral" view of time would mean building "minimal plans" which instead of prescribing rigid courses of action, would give organizational members the minimal structure (Hedberg et al., 1976; Weick, 1995) they need for coordination while fostering flexibility. This is close to Pentland and Reuter's (1994) concept of an organizational grammar that, like its conversational and linguistic counterpart, defines the set of rules needed for variety to emerge. This is also close to the role of the "strange attractors" in complexity theory, which are the structure necessary to foster adaptability (Stacey, 1996). In this sense, minimal plans or minimal constraints would amount to what Gearing (1958) called a structural pose, a set of behaviors and routines which is enacted again and again, providing the structure necessary for an organization to evolve. Within the parameters established by the minimal structure, people in the organization would be free to operate, innovate, and improvise as necessary to achieve the desired goals.

In summary, the combination of minimal plans and improvisation allows organizations to synthesize the past and the future in present allocation decisions, and is especially relevant in turbulent environments. When improvising, organizations use past routines in novel ways, revisiting the past while progressing in a path of evolution (Crossan et al., 1996; Hatch, 1998a/b; Moorman \& Miner, 1998a), moving ahead in circles--riding a spiral.

From the previous arguments, the following proposition is presented:

P3: Under conditions of high time pressure and/or uncertainty, a synthesis of linear-time and cyclical-time management through improvisation is associated with positive firm performance. 


\section{OBSTACLES TO SYNTHESIS}

The foregoing discussion presented theoretical possibilities for synthesis of three timebased phenomena. However, we see two primary obstacles to achieving synthesis in practice. The first obstacle is methodological and has been dealt with extensively elsewhere (e.g. Ancona, Goodman, Lawrence \& Tushman, 2001; Mitchell \& James, 2001). The critical point is that the challenges posed in studying time empirically are compounded by attempts to synthesize an already complex phenomena. Few measures exist for constructs such as even time or event time, and, therefore, developing measures of integrated constructs will be particularly challenging.

The second obstacle is the tension that exists between what may be required or deemed possible for organizations, and what individuals are likely to do. While we have espoused the virtues of an integrated view of time and the role improvisation plays in it, there is evidence to suggest that individuals as a whole do not operate in a manner to support such a view. For example, Waller, Conte, Gibson, and Carpenter's (2001) research on temporal orientation and deadlines, emphasizes that individuals differ in their perceptions of time urgency (the frequent concern with the passage of time) and time perspective (past, present, future orientation). In the case of time urgency, they note that it is a relatively stable individual-difference variable. Since these individual differences mirror the time dichotomies we have attempted to synthesize, it is questionable whether individual members in organizations have the capacity to achieve the espoused integration. Hope for the possibility of integration is held forth by Edward Hall, who, in an interview with Bluedorn (1998), notes that in spite of individual tendencies to a particular time orientation, he has observed what he refers to as a "high adaptive factor", which is an individual flexibility around time orientation. Clearly, future research will need to be mindful of this issue. 
Blount and Janicik (2001) examine the ability of organizational actors to adapt the timing of their activities to unanticipated events. They conclude that while temporal responsiveness-the ability of individuals to adapt their timing--may be critical for organizational performance, individuals create their own temporal references based on individual tendencies, non-work influences such as culture and family, and the surrounding work context. They suggest that "employees may be more effective in work environments in which their own personality-based temporal tendencies match those embedded within the surrounding organizational culture" (Blount \& Janicik, 2001: 579). Indeed, Slocombe and Bluedorn (1999) found that greater congruence between preferred and experienced work-unit time orientation was associated with higher levels of organizational commitment, the individual's perceived performance evaluation by the supervisor and co-workers, and perceived fairness of the performance evaluation. While this suggests the need for individual-organization fit, it does not address the need for organization-environment temporal fit. It is expected that lack of fit in either case will be associated with poor performance. The propositions presented in the previous sections of this study assume fit or integration between the individual and the organization, thereby focusing on the relationship between the organization and the environment. In each case, it was proposed that in environments of high time pressure and/or uncertainty, a synthesis through improvisation would be associated with better performance. The following propositions introduce the possibility and repercussions of the lack of temporal fit between the individual and organization.

P4: The greater the alignment between individual and organizational temporal orientations, the greater the individual job satisfaction.

P5: High temporal alignment between the organization and its environment is associated with positive firm performance, when there is temporal alignment between the individuals and the organization. 
We see two perspectives in dealing with this apparent mismatch between individual preferences and organization needs. The first is to question whether the academic community has an accurate interpretation of individual preferences. Since the research questions and instruments employed have not reflected a synthesized view of time, it is possible that present understanding is more reflective of current theory than it is of organizational reality. Obtaining a more accurate account of individual differences requires the development of instruments that capture a more integrated view of time, allowing for the possibility of a synthesis, not just dichotomies.

Assuming there is indeed a mismatch between individual preferences and organization needs, a second approach is that proposed by Ancona et al. (2001), who suggest the need for temporal leadership: "Teams enact temporal leadership as they entrain their organizations to technology and competitive cycles, manage across multiple time frames, and create temporal architectures for their organizations" (2001: 656). With an understanding of temporal issues it is expected that leadership may be able to set the context and guide the organization toward a more integrated and hence flexible approach to time. Essentially, this argues for the potential for leaders to manage temporal orientation, and create synthesis, where none may have previously existed.

Although not explicit, Blount and Janicik (2001) suggest the possibility that temporal orientation may be malleable when they state that "from an organizational perspective, the more readily individuals adjust their schedules to timing changes, the more agile and adaptive the organization will be" (2001: 572). And as previously stated, there may be a "high adaptive factor" (Bluedorn, 1998), where some individuals demonstrate flexibility in their temporal 
orientation. We extend this observation to suggest that leadership is the means through which individuals may adjust temporal orientations, as summarized in the following propositions.

P6: Temporal leadership may alter individual temporal orientations.

P7: Temporal leadership may alter organizational temporal orientations.

\section{CONCLUSIONS, IMPLICATIONS, AND DIRECTIONS FOR FUTURE RESEARCH}

We started this paper by recognizing the growing attention managers are paying to the management of time, where decisions about pace, rhythms, timing, and transitions have been positioned as strategically relevant. At the same time, we admitted that research on time in organizational settings is still scarce and that many of the efforts have been focused on conceptualizing opposite views of time such as Chronos or "objective" time and Kairos or "subjective" time. The main argument of this paper was that this contradiction in time perspectives is only apparent, and that by looking at organizational theory and practice, one can find that a synthesis between these opposing poles is not only possible, but also desirable for firms to remain competitive in today's dynamic environment. In this sense, we proposed that organizational improvisation--where time to plan converges with time to act--provides the space for organizations to enact synthesis by allowing even time to meet with event time, internal pacing to meet with external pacing, and linear time to meet with cyclical time.

We argue that despite the strong planning paradigm in the strategy field, managers need to be aware that, in practice, planning is often complemented by improvisation, and that it is important to recognize that there are times to plan and times to improvise. Under conditions of time pressure and/or uncertainty in the environment, improvisation allows for the convergence of 
planning and execution, and individuals make spontaneous use of their creativity and expertise to tackle unexpected problems or opportunities. We first reconciled even time and event time in scheduling processes, by showing how improvisation allows individuals to handle unexpected events, so that even time deadlines can be respected. In the same way, improvisers make use of even milestones when responding to unpredictable events. Second, we proposed that improvisation enabled a synthesis between internal and external pacing in synchronization processes. Improvisation allows organizations to respond to market rhythms without disturbing their own, yet the speed gained through improvisation may allow the firm to set the standard pace for the industry. Finally, we described how in allocation processes, improvisation synthesizes linear and cyclical time and enables the past and the future to be blended in present decisions. Improvisation creates something new, different from what existed before, but this novelty results from the rich combination of past expertise and knowledge.

This study contributes to both the literature on time and the literature on improvisation in organizations. First, our dialectic model of time represents an effort to integrate three fundamental bodies of knowledge on time. Ancona et al. (2001) note that research on time deals in particular with (1) conceptualizing time, (2) mapping activities to time, and (3) relating actors to time. They added that in order to advance research it was important for authors to clearly position their work and to build links and to integrate the knowledge in the three categories. This paper is an effort towards that integration. We proposed improvisation as the organizational practice through which temporal synthesis is achieved, and explained its role in managing firms' temporal problems: scheduling, synchronization, and allocation. Furthermore, we recognized the critical role of leadership and individual temporal orientations, and suggested the alignment between individual and organizational temporal orientations, and temporal 
leadership as antecedents of the desired synthesis. We believe that more integration efforts are needed in the future to advance knowledge in a field currently characterized by its fragmentation and lack of cumulative work.

Second, although some authors have proposed in the past that improvisation can help to reconcile organizational tensions, there are very few theoretical efforts that delve deeply into how this reconciliation is actually achieved. We sought to address this gap in the current understanding of the improvisation phenomenon and have described in this paper the practical ways in which improvisation enables temporal synthesis in scheduling, synchronization, and allocation processes. By doing this we hope to increase academic and managerial awareness not only about the incidence of improvisation in organizations, but also about the need to recognize those contexts under which improvisational processes provide value to firms. In addition, a managerial implication of this study is that it positions improvisation as critical skill in managing time, particularly in the context of turbulent environments.

We have attempted to anticipate obstacles to achieving synthesis by identifying methodological hurdles and practical hurdles involving the individual capacity to enact the proposed synthesis. We view synthesis as desirable, yet something that must be managed both in theory and practice. We join the growing number of voices pointing scholars and practitioners to incorporate time in their thinking and in their action. Theory has been time-blind for long enough and practice has still to tap the enabling power immanent in a more instrumental and conscious use of time as a vehicle for change. Additionally, on a broader level, we call on managers and scholars to look beyond the apparent contradiction many have been highlighting in organizational theory and practice, to understand it as a dialectical phenomenon where two opposites share mind-space and mind-time. 


\section{REFERENCES}

Academy of Management Review 2001. Special topic forum on time and organizational research. vol 26, no. 4.

Ancona, D. \& Chong, C.-L. 1996. Entrainment: Pace, cycle and rhythm in organizational behavior. Research in Organizational Behavior, 18: 251-284.

Ancona, D., Goodman, P., Lawrence, B. \& Tushman, M. 2001. Time: A new research lens. Academy of Management Review, 26: 645-663.

Ancona, D., Okhyusen, G. \& Perlow, L. 2001. Taking time to integrate temporal research. Academy of Management Review, 26: 512-529.

Barrett, F. 1998. Creativity and improvisation in jazz and organizations: Implications for organizational learning. Organization Science, 9: 543-555.

Berger, P. \& Luckmann, T. 1967. The social construction of reality: A treatise in the sociology of knowledge. London: Penguin.

Berliner, P. F. 1994. Thinking in jazz: The infinite art of improvisation. Chicago, IL. University of Chicago Press.

Bettis, R. A. \& Hitt, M. A. 1995. The new competitive landscape. Strategic Management Journal, 16: 7-19.

Bluedorn, A. C. 1998. An interview with anthropologist Edward T. Hall. Journal of Management Inquiry, 7: 109-115.

Bluedorn, A. C. \& Denhardt, R. B. 1988. Time and organizations. Journal of Management, 14: 299-319.

Blount, S. \& Janicik, G. 2001. When plans change: Examining how people evaluate timing changes in work organizations. Academy of Management Review, 26: 566-585.

Brown, S. L. \& Eisenhardt, K. M. 1997. The art of continuous change: Linking complexity theory and time-paced evolution in relentlessly shifting organizations. Administrative Science Quarterly, 42: 1-34.

Brown, S.L., \& K. Eisenhardt. 1998. Competing on the Edge: Strategy as Structured Chaos. Harvard Business School Press, Boston, Massachusetts, USA.

Burrell, G. 1992. Back to the future: Time and organization. In M. Reed \& M. Hughes, Eds., Rethinking organization: New directions in organizational theory and analysis: 165183. London: Sage.

Cavendish, R. 1982. Women on the line. London: Routledge.

Ciborra, C. U. 1999. Notes on improvisation and time in organizations. Accounting, Management \& Information Technology, 9: 77-94. 
Clark, P. 1978. Temporal innovations and time structuring in large organizations. In J. T. Fraser, N. Lawrence, \& D. Park, Eds., The study of time: 137-179. New York: Springer-Verlag.

Clark, P. 1985. A review of theories of time and structure for organizational sociology. Research in the Sociology of Organizations, 4: 125-176.

Clark, P. 1990. Chronological codes and organizational analysis. In J. Hassard \& D. Pym, Eds., The theory and philosophy of organizations: Critical issues and new perspectives: 137163. London: Routledge.

Cooper, R. G. 1979. The dimensions of industrial new product success and failure. Journal of Marketing, 43: 93-103.

Craig, A. \& Hart, S. 1992. Where to now in new product development research. European Journal of Marketing, 26: 2-49.

Crainer, S. 1997. Corporate man to corporate skunk: The Tom Peters phenomenon. London: Capstone.

Crossan, M. 1998. Improvisation in action. Organization Science, 9: 593-599.

Crossan, M. \& Sorrenti, M. 1997. Making sense of improvisation. Advances in Strategic Management, 14: 155-180.

Crossan, M., Lane, H., White, R. E., \& Klus, L. 1996. The improvising organization: Where planning meets opportunity. Organizational Dynamics, 24: 20-35.

Cunha, M. P., Cunha, J. V., \& Kamoche, K. 1999. Organizational improvisation: What, when, how and why. International Journal of Management Reviews, 1: 299-341.

D'Aveni, R. A. 1995. Coping with hypercompetition: Utilizing the new 7-S's framework. Academy of Management Executive, 9: 45-57.

Das, T. K. 1993. Time in management and organizational studies. Time and Society, 2: 267-274.

DeGeus, A. 1997. The living company. Cambridge, MA: Harvard Business School Press.

Deschamps, J. P. \& Nayak, P. R. 1995. Product juggernauts: How companies mobilize to generate a stream of market winners. Boston, MA: Harvard Business School Press.

Ditton, J. 1979. Baking time. Sociological Review, 27: 157-167.

Eisenhardt, K. M. 1997. Strategic decision making as improvisation. In V. Papadakis \& P. Barwise, Eds., Strategic decisions: 251-257. Norwell, MA: Kluwer.

Eisenhardt, K. M. \& Brown, S. L. 1998. Time pacing: Competing in markets that won't stand still. Harvard Business Review, 59-69.

Eisenhardt, K. M. \& Tabrizi, B. N. 1995. Accelerating adaptative processes: Product innovation in the global computer industry. Administrative Science Quarterly, 40: 84-110. 
Ellis, R. J. 1982. Improving management response in turbulent times. Sloan Management Review, 23: 3-11.

Filipcove, B. \& Filipovec, J. 1986. Society and concepts of time. International Social Sciences Journal, 107: 19-32.

Frost, P. J. 1995. The many facets of creativity. In C.M. Ford \& D.A. Gioia, Eds., Creative action in organizations: $121-130$. Thousand Oaks, CA: Sage.

Gearing, E. 1958. The structural poses of the 18th century cherokee villages. American Anthropologist, 60: 1148-1157.

Gersick, C. G. J. 1991. Revolutionary change theories: A multilevel exploration of the punctuated equilibrium paradigm. Academy of Management Review, 32: 274-309.

Gersick, C. J. \& Hackman, J. R. 1990. Habitual routines in task performing groups. Organizational Behavior and Human Decision Processes, 47: 65-97.

Gherardi, S. \& Strati, A. 1988. The temporal dimension in organizational studies. Organization Studies, 9: 149-164.

Goodman, P., Lawrence, B., Ancona, D. \& Tushman, M. 2001. Introduction. Academy of Management Review, 26: 507-511.

Hamel, G. \& Prahalad, C. K. 1994. Competing for the future: Breakthrough strategies for seizing control of your industry and controlling the markets of tomorrow. Boston: Harvard Business School Press.

Hassard, J. 1996. Images of time in work and organization. In S. R. Clegg, C. Hardy, \& W. R. Nord, Eds., Handbook of organization studies: 581-598. Thousand Oaks, CA: Sage.

Hatch, M. J. 1997. Jazzing up the theory of organizational improvisation. Advances in Strategic Management, 14: 181-191.

Hatch, M. J. 1998a. Exploring the empty spaces of organizing: How improvisational jazz redescribes organizational structure. Organization Studies.

Hatch, M. J. 1998b. Jazz as a metaphor for organizing in the $21^{\text {st }}$ century. Organization Science, 9 (5): 556-557.

Hedberg, B. L. T., Nystrom, P. C., \& Starbuck, W. H. 1976. Camping on seesaws: Prescriptions for self-designing organizations. Administrative Science Quarterly, 21: 41-65.

Holmer-Nadesan, M. 1997. Essai: Dislocating (instrumental) organizational time. Organization Studies, 18 (3): 481-510.

Hughes, E. C. 1971. The sociological eye. New York: Aldine.

Iansiti, M. 1995. Shooting the rapids: Managing product development in turbulent environments. California Management Review, 38, 1: 37-58.

Jaques. E. 1982. The form of time. London: Heinemann. 
Johnson, B. M. \& Rice, R. E. 1984. Reinvention in the innovation process: The case of word processing. In R. E. Rice, Ed., The new media: 157-183. Beverly Hills: Sage.

Kamoche, K. N. \& Cunha, M.P. 2001. Minimal structures: From jazz improvisation to product innovation. Organization Studies, 22, 733-764.

Kao, J. 1997. Jamming. New York: Harper Collins.

Katz, R. 1980. Time and work: Toward an integrative perspective. Research in Organizational Behavior, 2: 81-127.

Kavanagh, D. \& Araujo, L. 1995. Chronigami: Folding and unfolding time. Accounting, Management \& Information Technology, 5: 103-121.

Lawrence, P. R. \& Lorsch, J. W. 1967. Organization and environment. Cambridge, MA: Harvard University Press.

Leonard, D. 1995. Wellsprings of knowledge: Building and sustaining the sources of innovation. Boston, MA: Harvard Business School Press.

Maturana, H. R. \& Varela, F. J. 1980. Autopoiesis and cognition: The realization of the living. Dordecht, The Netherlands: D. Reidel Publishing.

McGrath, J. E. \& O’Connor, K. M. 1996. Temporal issues in work groups. In M. A. West, Ed., Handbook of work and group psychology: 25-52. London: John Wiley \& Sons.

McGrath, J. E. \& Rotchford, N. L. 1983. Time and behavior in organizations. Research in Organizational Behavior, 5: 57-101.

Micklethwait, J. \& Wooldridge, A. 1996. The witch doctors: What the management gurus are saying, why it matters and how to make sense of it. London: William Heinemann.

Miner, A. S., Bassoff, P. \& Moorman, C. 2001. Organizational improvisation and learning: A field study. Administrative Science Quarterly, 46, 304-337.

Mintzberg, H. 1994. The rise and fall of strategic planning. New York: Free Press.

Mintzberg, H. \& McHugh. 1985. Strategy formation in an adhocracy. Administrative Science Quarterly, 30: 160-198.

Mitchell, T. \& James, L. 2001. Building better theory: Time and the specification of when things happen. Academy of Management Review, 26: 530-547.

Moorman, C., \& Miner, A. 1995. Walking the tightrope: Improvisation and information use in new product development. Marketing Science Institute Report No. 95-101, Cambridge, MA: Marketing Science Institute.

Moorman, C. \& Miner, A. 1998a. The convergence between planning and execution: improvisation in new product development. Journal of Marketing, 62: 1-20.

Moorman, C. \& Miner, A. 1998b. Organizational improvisation and organizational memory. Academy of Management Review, 23: 698-723. 
Orlikowski, W. J. 1996. Improvising organizational transformation over time: A situated change perspective. Information Systems Research, 7(1): 63-92.

Orlikowski, W. J. \& Yates, J. 1998. It's about time: An enacted view of time in organizations. Proceedings of the 58th Annual Meeting of the Academy of Management. San Diego, CA: Academy of Management.

Pascale, R. T. 1984. Perspectives on strategy: The real story behind Honda's success. California Management Review: 25: 47-72.

Pascale, R. T. 1995. The Honda effect. In H. Mintzberg, J. B. Quinn, \& S. Ghoshal, Eds., The strategy process: European edition: 125-134. Hertfordshire, UK: Prentice Hall.

Pascale, R. T. 1999. Surfing the edge of chaos. Sloan Management Review, 83-94.

Pentland, B. T. \& Reuter, H. H. 1994. Organizational routines as grammars of action. Administrative Science Quarterly, 39: 484-510.

Perry, L. T. 1991. Strategic improvising: How to formulate and implement competitive strategies in concert. Organizational Dynamics, 19: 51-64.

Peters, T. J. 1992. Liberation management: The necessary disorganization for the nanosecond nineties. New York: Alfred A. Knopf.

Peters, T. \& Waterman, R. 1982. In search of excellence. New York: Harper and Row.

Rerup, C. 2001 "Houston, we have a problem": Anticipation and improvisation as sources of organizational resilience. Comportamiento Organizacional e Gestao, 7: 27-44.

Roux-Dufort, C. \& Vidaillet, B. 2001. From normalization to improvisation in crisis management: $A$ case study. Unpublished manuscript.

Shapiro, E. 1995. Fad surfing in the boardroom: Reclaiming the courage to manage in the age of instant answers. Reading, MA: Addison-Wesley.

Slocombe, T. E. \& Bluedorn, A. C. 1999. Organizational behavior implications of the congruence between preferred polychronicity and experienced work-unit polychronicity. Journal of Organizational Behavior, 20, 75-00.

Smircich, L. \& Stubbart, C. 1985. Strategic management in an enacted world. Academy of Management Review, 26: 724-736.

Stacey, R. D. 1991. The chaos frontier: Creative and strategic control for business. Oxford: Butterworth-Heinemann.

Stacey, R. D. 1996. Complexity and creativity in organizations. San Francisco: Berrett-Koehler.

Stalk, G. \& Hout, T. M. 1990. Competing against time: How time based competition is reshaping global markets. New York: Free Press.

Thomke, S. 1998. Managing experimentation in the design of new products. Management Science, 44, 6, 743-762. 
Tyre, M. J., Perlow, L., Staudenmayer, N., \& Wasson, C. 1996. Time as a trigger for organizational change. Proceedings of the 56th Annual Meeting of the Academy of Management. Cincinnati, OH: Academy of Management.

Vera, D. \& Crossan, M. 2001. Improvisation: A theoretical model of its dimensions and its impact on performance. Working Paper. The University of Western Ontario, Richard Ivey School of Business, London, ON, Canada.

Waller, M. J., Conte, J., Gibson, C. \& Carpenter, M. 2001. The effect of individual perceptions of deadlines on team performance. Academy of Management Review, 26: 586-600.

Waller, M. J., Gibson, C. B., \& Carpenter, M. A. 1999. Time's arrow: The impact of differences in time perspective on knowledge management speed in multicultural teams. Proceedings of the 59th Annual Meeting of the Academy of Management. Chicago, IL: Academy of Management.

Weick, K. E. 1979. The social psychology of organizing (2nd. Ed.). New York: McGraw-Hill.

Weick, K. E. 1993. The collapse of sensemaking in organizations: The Mann Gulch disaster. Administrative Science Quarterly, 38 (4): 628-652.

Weick, K. E. 1995. Sensemaking in organizations. Thousand Oaks, CA: Sage.

Weick, K. E. 1998a. The attitude of wisdom: Ambivalence as the optimal compromise. In S. Srivastva \& D. Cooperrider (Eds.), Organizational wisdom and executive courage: 40-64. San Francisco: New Lexington Press.

Weick, K. E. 1998b. Improvisation as a mindset for organizational analysis. Organization Science, 9: 543-555.

Weick, K. E. 1999. The aesthetic of imperfection in organizations. Comportamento Organizacional e Gestão, 5: 5-22.

Weick, K. E. 2001. Substitutes for strategy. Making sense of the organization: 345-355. Malden: MA: Blackwell.

Zerubavel, E. 1982. The standardization of time: A sociohistorical perspective. American Journal of Sociology, 88: 1-23.

Zerubavel, E. 1987. The language of time: Towards a semiotics of temporality. The Sociological Quarterly, 28: 343-356. 